\title{
Nitrogen isotope compositions of the Chang 7 Shale,the Ordos Basin, north China: implications of depositional redox changes
}

\author{
RUIQIAN CHEN ${ }^{1}$
}

${ }^{1}$ College of Geosciences, China University of Petroleum (Beijing), Beijing 102249, China, richen@cup.edu.cn

\footnotetext{
Nitorgen isotope $\left(\delta^{15} \mathrm{~N}\right)$ analysis has been used to evaluate depositional redox conditions in well-preserved sedimentary systems, however, less $\mathrm{N}$-isotope studies have been made to reconstruct the redox changes in lacustrine shales. In this paper, we report the $\delta^{15} \mathrm{~N}$ data from the Upper Triassic Chang 7 Shale of the Ordos Basin, north China. Bulk $\delta^{15} \mathrm{~N}$ values are significantly higher in the Chang 73 and the lower part of the Chang 72 submembers (Zone A; average $=$ $9.4 \pm 1.3 \%$ ) than in the upper part of the Chang $7_{2}$ and the Chang 71 submembers (Zone B; average $=5.4 \pm 1.5 \%$ ). Lithological aspects of these deposits and previous geochemical measurements suggest that Zone A were mainly deposited under suboxic bottom water conditions, whereas Zone B deposits accumulated within an oxygenated water column. Stable organic carbon isotopes $\left(\delta 13 \mathrm{C}_{\mathrm{org}}\right)$ and total nitrogen (TN) values of the two zones display little variation that could be attributed to changing organic matter sources and/or post-depositional alteration of $\delta^{15} \mathrm{~N}$. Thus, we suggest that changes of $\delta^{15} \mathrm{~N}$ through the Chang 7 Shale primarily reflect differences in depositional redox conditions and $\delta^{15} \mathrm{~N}$ values of shale can provide important details regarding the depositional history of unconventional resource plays.
} 